\title{
BRASIL: REALIDADES MASCARADAS E O PAPEL DO BINÔMIO JUSTIÇA- FRATERNIDADE NA PANDEMIA PROVOCADA PELA COVID-19
}

\author{
Taíza Maria Alves da Silva ${ }^{1}$ \\ Dávila Teresa de Galiza Fernandes Pinheiro ${ }^{2}$ \\ Marcelle Rayanna Nanes de Freitas ${ }^{3}$ \\ DOI: https://doi.org/10.47306/978-65-88213-03-2.286-301
}

Sumário: 1 Introdução; 2 A pandemia e as evidências das desigualdades do contexto brasileiro: uma análise sociojurídica; $3 \mathrm{O}$ binômio justiça-fraternidade como meio de repensar os vazios das desigualdades; 4 Experimentalismos fraternais: desafios e perspectivas; 5 Considerações finais; Referências.

\section{Introdução}

A atual pandemia provocada pela Covid-19, revelou, em ordem global, muitas das mazelas estruturais, institucionais e humanas do modelo de desenvolvimento políticoeconômico vigente no sistema capitalista.

Uma característica que observamos no nosso tempo é que grande parte da sociedade se move impulsionada pela busca da própria utilidade pessoal e se olvida, facilmente, em agir de acordo com práticas mais inclusivas, que sejam capazes de dividir e multiplicar, ao invés de somar e acumular para si próprio. O que se apresenta evidente na esfera econômica, reverbera de modo ainda mais nítido no âmbito social, pois o crescimento econômico não foi capaz de gerar, proporcionalmente, o desenvolvimento social. Ao invés de um modelo inclusivo, fez emergir um cenário de exclusão, marginalidade e desigualdades sociais.

$\mathrm{O}$ vírus tem potencial de atingir a todos, sem distinguir cor de pele, classe social, língua, enfim, não conhece fronteiras, “é uma figura sistêmica da globalização” (RECALCATI, 2020,

\footnotetext{
${ }^{1}$ Doutora em Direito pela Universidade do Minho/Portugal. Mestre em Filosofia pela UFPB. Professora da ASCES UNITA e da Unifavip. Pesquisadora do Grupo Teoria e História dos Direitos Humanos e da Democracia do Núcleo de Cidadania e Direitos Humanos/UFPB.E-mail: taiza.maria@gmail.com

${ }^{2}$ Mestre em Direitos Humanos, Cidadania e Políticas Públicas pela UFPB. Professora do Centro Universitário Tabosa de Almeida - ASCES UNITA e pesquisadora do Instituto de Estudos Avançados - IEA ASCES UNITA e do Grupo Teoria e História dos Direitos Humanos e da Democracia da UFPB. E-mail: davilagaliza@hotmail.com ${ }^{3}$ Graduanda em Direito pela ASCES UNITA. Monitora no Projeto de Extensão Núcleo Civitas. Monografia de conclusão de curso aprovada em junho/2020 com o tema: "Direitos Humanos e Fraternidade: uma análise do constitucionalismo fraternal na defesa dos direitos humanos”. E-mail: marcellerayanna@gmail.com
} 
$\mathrm{s} / \mathrm{p}$ ). E foi ultrapassando fronteiras, que a pandemia pôde revelar o quanto o direito à igualdade e à dignidade humana são banalizados pela maioria das democracias modernas. Enquanto uns possuem acesso à infraestrutura, água potável, máscaras, itens de higiene (como desinfetantes a base de álcool), acesso à internet ${ }^{4}$, outros, em situação de total vulnerabilidade, são preteridos do desenho político institucional e sofrem as injustiças desse sistema.

Ao longo dos tempos, o modelo neoliberal trouxe "a redução da vida a valor econômico; a negação do público e do comum; o indivíduo como valor absoluto e a redução da alteridade do outro à lógica utilitarista do interesse próprio" (RUIZ, 2020, s/p). Esse raciocínio traz à tona o epicentro das desigualdades presentes, sobretudo nos países em vias de desenvolvimento. Um vírus invisível gerando ainda mais invisibilidades aos mais necessitados.

Como há décadas apontava Darcy Ribeiro (2006, p. 194), “no Brasil, as classes ricas e as pobres se separam umas das outras por distâncias sociais e culturais quase tão grandes quanto as que medeiam entre povos distintos", de modo que aquelas não poderiam ser representadas por um triângulo - representação comum das estratificações sociais - mas por um losango, com um ápice finíssimo. Assim, quando neste trabalho mencionamos o termo desigualdade, estamos nos referindo ao seu vértice social, e mais especificamente aquele que durante a pandemia da Covid-19 explicitou os abismos que nos separam, enquanto brasileiros.

Parafraseando Eduardo Galeano 5 (2000), diante dessas “veias abertas” de desigualdades que escorrem no Brasil, especificamente, nas regiões de maior vulnerabilidade socioeconômica, de que modos esses vazios de justiça social poderiam ser atenuados, a fim de minimizar os abismos de injustiças sociais?

Partindo desta pergunta, pretendemos através do método dedutivo, analisar inicialmente o panorama da pandemia causada pelo novo coronavírus, que, ao adentrar no Brasil, está evidenciando com maior nitidez as desigualdades sociais, expondo as lacunas ou os vazios de justiça social. Em um segundo momento, intentamos avaliar essa conjuntura, a partir do enfoque metodológico da justiça relacional, em seu aspecto de intersecção com a fraternidade (binômio justiça-fraternidade). Por fim, num terceiro momento, buscar-se-á trazer o alcance de experimentalismos fraternos vivenciados em alguns cenários do Brasil, como forma de

\footnotetext{
${ }^{4}$ Ferramenta que tem se demonstrado indispensável para acompanhar os desafios apresentados em razão do distanciamento social, a exemplo das aulas remotas no ensino ou mesmo os benefícios prestados pelo governo federal, em que somente terá acesso aqueles que manejam o uso de aplicativos digitais que dependem da internet para funcionarem em seus devidos fins.

${ }^{5}$ A título de conhecimento desta obra do autor, segue referência: GALEANO, E. As veias abertas da América Latina. Tradução de Galeno de. Freitas. 39a ed. Rio de Janeiro: Paz e Terra, 2000. 307p.
} 
verificar, na prática, alguns resultados que identificamos com a mudança cultural que está sendo suscitada pelo "novo normal": do individual ao fraternal.

\section{A pandemia e as evidências das desigualdades do contexto brasileiro: uma análise sociojurídica}

Não nos parece difícil enumerar as diversas faces da desigualdade no Brasil. É um fenômeno naturalizado, que produz subcidadãos em massa (SOUZA, 2006) e com o qual convivemos, tantas vezes indiferentes, aos seus efeitos em grande escala ou à conta-gotas. Lilia Schwarcz (2019) se refere a uma desigualdade enraizada, sendo possível identificar algumas das suas origens (mão de obra escrava, patrimonialismo, corrupção), embora isso não dê conta de esclarecer por que não conseguimos romper com seu círculo vicioso.

Nada obstante, não intentamos tratar da nossa "gestação como povo", na expressão de Darcy Ribeiro (2006). Neste primeiro tópico nos propomos a refletir sobre uma situaçãoproblema específica, qual seja, um "distanciamento social” que marca a nossa história, mas desde a colonização e que foi evidenciado no contexto da pandemia da Covid-19: aquele entre os estratos sociais, que nos desgarra em componentes opostos "debaixo da uniformidade étnicocultural e da unidade nacional" (RIBEIRO, 2006, p. 21).

De antemão, cabe destacar que a relação entre a desigualdade social e a maior vulnerabilidade ao contágio e/ou morbidade pelo vírus não é um fenômeno exclusivo do Brasil. A História tem registros das relações entre as grandes tragédias humanas envolvendo doenças e a população mais vulnerável, bem como estudos recentes publicados nos Estados Unidos atualizam e demonstram tal constatação. Abrams e Szefler (2020) destacam, dentre outros aspectos, que o fechamento das escolas aumentou a insegurança alimentar das crianças pobres, a desnutrição causa diminuição da resposta imune, e que as pessoas desabrigadas correm maior risco de infecção durante bloqueios físicos, sobretudo se os espaços públicos estiverem fechados. Ademais, os autores apresentam o quanto determinantes sociais da saúde como a pobreza, o ambiente físico, a falta de moradia, ou mesmo a raça e a etnia, podem refletir nos resultados da Covid-19.

Contudo, nossos olhos se voltam para pensar nossa desigualdade social sob a perspectiva dos indicativos recentes e o contexto que entendemos revelar particularidades da pandemia no Brasil. Para tal, partimos não de planilhas numéricas, mas da recomendação fortemente repetida pela Organização Mundial da Saúde (OMS), que, ante a não existência de uma vacina, apontou o distanciamento físico como principal estratégia de proteção no momento 
histórico em que vivemos. O necessário isolamento social tem reverberado entre a população através do indicativo: "fique em casa". Mas, será que o substantivo casa nos indica realidades equânimes? Bem sabemos que não.

Para o imenso contingente de brasileiros que vive nas favelas, em situação de cárcere ou de extrema pobreza, nas aldeias ou nas ruas, o "ficar em casa" não se torna necessariamente uma medida eficiente para a prevenção e o controle da Covid-19. Falta-lhes, em grande parte, o acesso ao mais elementar que dignifica a condição humana, como acesso à saúde, água potável, saneamento básico, direitos trabalhistas que assegurem as suas permanências no ambiente doméstico, uma renda mínima, o suporte unificador e adequado do Estado ou uma casa para ficar.

O Conselho Nacional de Saúde ${ }^{6}$ emitiu nota pública em que lamentou as mortes de 50.667 brasileiros e brasileiras (dados em 21 de junho de 2020), registrou que se tratavam de mortes evitáveis, se não tivesse ocorrido o desfinanciamento do Sistema Único de Saúde (SUS) e se "o Estado e as autoridades governamentais tivessem assumido a responsabilidade de coordenar as ações de enfrentamento à Covid-19, respeitando as medidas adequadas”. A nota se referia, especificamente, às orientações da Organização Mundial da Saúde, registradas na Nota como sendo seguidas pela maioria dos países que enfrentam a pandemia no mundo.

Estamos todos sob a mesma tempestade e participamos do mesmo esforço coletivo
para não deixar a população à deriva. Mas não estamos no mesmo barco. A
desigualdade social encontrada no Brasil é um terreno fértil para a disseminação da
COVID-19, dificultando o isolamento social, restringindo acesso a insumos básicos
para higiene e proteção, e dificultando a própria assistência aos serviços de Saúde. A
disparidade entre o número de leitos e respiradores per capita na rede pública e privada
gera distorções que dificultam a distribuição eficaz de recursos, contribuindo para a
mortalidade. (MINAYO; FREIRE, 2020). (grifos nossos)

Nesta perspectiva, Lemos e Rego (2020) apontam que "o sonho sanitarista de um modelo de atenção à saúde público, universal e gratuito, consagrado na Constituição Federal de 1988, sempre foi minado por entes interessados em favorecer o sistema privado". Os autores reforçam que a pandemia implicou num aumento da demanda por leitos de UTI, o que tem levado o SUS ao limite de sua capacidade na maior parte das cidades brasileiras. Daí apontarem para a "face real de uma estrutura necropolítica", na qual a população mais vulnerável tem sido vítima da omissão do poder público e remonta ao neologismo de Márcio Fabri, qual seja, de uma mistanásia, descrita pelos mesmos como "morte infeliz, miserável e evitável”, ou seja, desamparada pela dignidade.

\footnotetext{
${ }^{6}$ O Conselho Nacional de Saúde - CNS, regulamentado pela Lei n 8.142/1990 "é uma instância colegiada, deliberativa e permanente do Sistema Único de Saúde (SUS), integrante da estrutura organizacional do Ministério da Saúde" no Brasil. Fonte: https://conselho.saude.gov.br/apresentacao/apresentacao.htm
} 
São questões complexas, que ultrapassam as fronteiras do fenômeno epidemiológico, e nos levam a refletir sobre o acesso aos direitos fundamentais sociais e o princípio da dignidade da pessoa humana. Quanto aos primeiros, há décadas o professor J. J. Gomes Canotilho (1998) já se referia à indeterminação dos direitos sociais nos ordenamentos jurídicos, inclusive referindo-se a estes a partir de uma metodologia "fuzzy" (coisas vagas) e/ou "camaleões normativos". Também neste sentido, Holmes e Sustein (1999) afirmam que se os direitos têm dentes, os direitos sociais parecem ter a mordedura mais leve. É narrativa constante a respeito destes direitos - mesmo não negando a sua fundamentalidade - que eles custam caro ao Estado e, em caso de escassez de recursos públicos, são os direitos sociais os primeiros a não serem atendidos.

Quanto à referência aqui expressa à dignidade da pessoa humana, somos conscientes que esta ideia remete a interpretações distintas, seja fundada nos preceitos bíblicos, nos ideais iluministas ou na metafísica dos costumes kantiana. Contudo, a partir de Hannah Arendt (1989, p. 332), intentamos reavivar a importância da reflexão sobre a dignidade como "o direito a ter direitos" e enquanto fundamento da República Federativa do Brasil. Esta que, ao ser prevista desde o artigo primeiro, traz consigo uma carga simbólica e fundante, que deveria ser o norte de todo o ordenamento jurídico e constitucional, pois, como nos lembra Gilmar Mendes (2013) se trata do "direito fundamental de todos os direitos fundamentais".

Neste contexto potencialmente letal que, sem precedentes na história nos desafia a sobreviver, mas também a pensar num Brasil pós-pandemia, encerramos esta seção com uma reflexão proposta por uma representante da população indígena. Esta que, com sua vivência comunitária e historicamente desassistida na garantia de direitos fundamentais consagrados a todos (como o direito à saúde e ao seu território), é apontada pelo Conselho Nacional de Saúde, como um dos grupos mais vulneráveis no contexto da pandemia. Para aqueles, o "fique em casa", além de implicar numa adaptação para um "fique na aldeia", pode levar a sentidos mais profundos. Segundo a líder indígena Célia Xakriabá, do território Xakriabá, localizado em Minas Gerais, em entrevista à Revista Radis, "é muito mais uma reflexão sobre 'Fique na sua primeira casa', que é nosso próprio corpo, para repensar o comportamento do nosso ser no mundo", e acrescenta que, além de uma guerra biológica, estamos diante de uma "guerra civilizatória que requer outro modo de vida" (STEVANIM, 2020, p. 10). Poderão o direito e a fraternidade nos apontar caminhos para este novo mundo? Sigamos refletindo. 


\section{$3 \mathrm{O}$ binômio justiça-fraternidade como meio de repensar os vazios das desigualdades}

A inquietação exposta nas primeiras linhas do tópico anterior abre o presente, qual seja: podemos até identificar e apontar as possíveis origens das desigualdades históricas internalizadas em nosso país, mas isso não esclarece o porquê não conseguimos romper com esse círculo vicioso das desigualdades.

Todavia, um ponto nos parece consensual, as desigualdades implicam diretamente em injustiças sociais e estas ferem frontalmente o princípio da dignidade humana. E é a partir desta constatação que intencionamos analisar neste tópico a abordagem metodológica proposta pela justiça relacional ${ }^{7}$, a qual pretende ser aplicada contextualizando-se ao cenário atual de crise pandêmica.

Nas palavras do autor deste enfoque metodológico, Prof. Antonio Márquez Prieto, "por si misma, la expresión 'justicia relacional' alude a un criterio u orientación de análisis: la búsqueda de la justicia en la relación, o el examen de la relación, según su grado de justicia” (PRIETO, 2012, p. 55) ${ }^{8}$. O que significa dizer, em apertada síntese, que, a proposta deste enfoque intenciona identificar a presença ou ausência de justiça nas relações jurídicas que, antes de mais nada, são relações sociais.

Desse modo, ao mencionar "ausência de justiça" ou "vazios de justiça" nas relações, intencionamos apontar a existência de injustiças. Sendo possível aduzir, desde já, que a raiz dos vazios de justiça demonstra, por si só, algum tipo de desequilíbrio de caráter relacional entendida a relação como vínculo recíproco, ou seja, vinculação e reciprocidade (PRIETO, $2012^{9}$ ). E, dentre as diversas perspectivas possíveis de análise à luz deste enfoque, trataremos aqui da concepção de justiça social nos vínculos entre os sujeitos (vínculos interpessoais, e institucionais que orientam, por exemplo, autoridades públicas, agentes e instituições em geral em suas mais diversas relações), a fim de verificar a presença ou ausência de justiça na dinâmica

\footnotetext{
${ }^{7}$ O precursor deste enfoque metodológico é o Prof. Dr. Antonio Márquez Prieto, professor Catedrático das Faculdades de Direito e de Estudos Sociais, bem como do Programa de Doutorado em Ciências Jurídicas e Sociais, além de Diretor do Departamento de Direito do Trabalho e da Seguridade Social da Universidade de Málaga-ES. O Prof. Prieto, com uma rede temática interdisciplinar de professores e pesquisadores das mais diversas áreas do conhecimento, principalmente nas áreas do direito e da economia, se debruçam no estudo sistemático da justiça relacional há mais de uma década.

${ }^{8}$ Trata-se, segundo o próprio autor, de um novo olhar para o direito (que se amplia à concepção de justiça), a partir do "giro relacional" proporcionado pela sociologia, o que foi possível vir à tona a partir das contribuições do sociólogo Pierpalo Donati. Para um maior aprofundamento do conhecimento deste enfoque, recomendamos a leitura de: DONATI, Pierpaolo. Repensar la sociedad: El enfoque relacional. Madrid: Eiunsa, 2006.

9 “(...) la idea de justicia encuentra explicación desde la noción de relación, que es vínculo recíproco, es decir, vinculación y reciprocidad. La justicia es su efecto emergente si nos situamos en una relación o sistema jurídicos, cuyas referencias, internas y externas, se orienten hacia la misma de forma intencional" (PRIETO, 2012, p. 61).
} 
relacional criada ou já estabelecida, o que poderá fornecer norteamentos para descontinuar o círculo vicioso das desigualdades brasileiras.

É preciso, inicialmente, identificar as dimensões relacionais propostas por este enfoque metodológico, a fim de evidenciar as realidades mascaradas produtoras de abismos de desigualdades no Brasil, para, em seguida, ser possível oferecer subsídios capazes de minimizar esses vazios de justiça, consoante fora exposto.

Três são as dimensões relacionais: institucionalidade, reciprocidade e socialidade. Convém, portanto, realizar algumas ponderações sobre referidas componentes, sem nenhuma pretensão de reduzir seu vasto conteúdo epistemológico. O professor Prieto (2012) demonstra que a relação se desenvolve em base a uma dinâmica bilateral assentada em dois eixos: um eixo estrutural (representado, por exemplo, por uma instituição, um corpo normativo ou um ordenamento jurídico) e um eixo dinâmico (reciprocidade ou comportamento recíproco).

Na medida em que o eixo estrutural atua em consonância com os valores de justiça, boafé, equidade, orientado ao bem coletivo (comportamento relacional), por exemplo, há maior probabilidade de produzir justiça na relação. Do contrário, se age em busca de interesses pessoais, deixando à margem, a consecução dos interesses públicos, é capaz de provocar ainda mais vazios de justiça ou injustiças sociais. Logo, se as institucionalidades (representadas, por exemplo, pelas normas editadas pelos órgãos competentes para encontrar meios de superar a pandemia ou pelos próprios agentes públicos representantes do poder em suas três esferas: municipal, estadual e federal) seguem descuidando-se da situação de crise, engrenando em episódios perenes de corrupção, sem qualquer preocupação com o controle e equilíbrio do orçamento público, convertendo a própria política em um mercado de utilidade pessoal (LIANZA, 2017), dificilmente, haverá soluções para a crise que estamos inseridos.

Desse modo, a depender da conduta (ação ou omissão) da institucionalidade ${ }^{10}$ — a justiça poderá ser produzida ou não. Nesse caso, importa destacar que o comportamento/conduta diz respeito a parte axiológica da estrutura do enfoque relacional, traduzida na expressão da reciprocidade (estrutura dinâmica, ideal, onde se opera as interações, onde se detecta de maneira visível os "vazios de justiça").

Finalmente, dentro da dinâmica criada entre referidos eixos - institucionalidade e reciprocidade -, é que, de acordo com Prieto, se produz a terceira componente da justiça relacional: a socialidade, compreendida como "o espaço onde acontecem as relações,

\footnotetext{
${ }^{10}$ O que, segundo Miranda (2016, p. 121) "deve ser vista não somente como institucionalidade do ponto de vista formal, mas compreendê-la envolvendo o tipo e a intensidade do vínculo estabelecido entre os sujeitos", incluídos na própria dinâmica da reciprocidade.
} 
configurando ao mesmo tempo o elemento gerador da dinâmica da justiça relacional e o resultado final produzido a partir da justiça como efeito emergente da relação" (MIRANDA, 2016, p. 122). Nesse espaço de socialidade, onde as relações se sucedem ou deveriam suceder, convém trazer à tona o caráter necessariamente emancipador e libertador da justiça social no que tange às estruturas sociais desumanas de subordinação, dependência e dominação (PRIETO, 2008), fazendo-se necessário quebrar este círculo vicioso, substituindo-o por um círculo virtuoso de justiça, capaz de promover dignidade a todos os seres humanos.

Nesse sentido, convém elucidar que a relacionalidade sugerida como marco do enfoque da justiça relacional “(...) exige la inserción, la inclusión en una relación propiamente interpersonal, un ajuste (autónomo o heterónomo) de lo asimétrico con lo horizontal, de la dependencia con la interdependencia por medio del 'expediente de inclusión"” (PRIETO, 2008, p. 52-53).

A partir desta perspectiva, faz sentido encontrar, nesse espaço de socialidade promovido pela justiça relacional, o princípio da fraternidade, enquanto uma nova forma de conceber a relação (PRIETO, 2012, p. 79), na concepção de um novo agir que também abarca a reciprocidade e a própria relacionalidade ${ }^{11}$. Em outras palavras, o binômio justiça-fraternidade pode se referir a uma realidade social relacional. Assim, podemos dizer que "os vazios de justiça constituem também vazios de fraternidade" (PRIETO, 2012, p. 86), encontrados nas relações assimétricas de subordinação e dependência, que acaba por produzir exclusão, injustiças e desigualdades sociais.

Percebe-se, portanto, que nas estruturas sociais onde se apresentam grandes déficits de igualdade (na concepção material) e de justiça social, os vazios de justiça são preenchidos por uma relação de supremacia hierárquica, ou imposição hegemônica ditadas por relações de poder (PRIETO, 2012). Para exemplificar um pouco, importa assinalar que, numa crise como a que estamos vivenciando a nível global, no mínimo, duas reações distintas podem ser adotadas pelas institucionalidades que representam a classe dirigente político-econômica de um país: a adoção de soluções autoritárias e fortemente intervencionistas (LIZANA, 2017, p. 39) ou a solução coletiva para os problemas a partir da adoção de medidas concretas que contemplem o bem das coletividades, através, por exemplo, da adoção de políticas públicas emergenciais (ou de caráter duradouro), a fim de assegurar uma adequada infraestrutura ao país.

\footnotetext{
11 "Precisamente el ámbito de socialidad es el que puede expresar - o no- una fraternidad viva y continuamente inventada. Pero es el ámbito de reciprocidad el que da la posibilidad de 'entrar' en la fraternidad". (PRIETO, 2012, p. 80)
} 
Igualmente, no que tange às relações interpessoais, o advento de uma crise, poderá desencadear dois particulares tipos de comportamento: o crescente aumento da individualidade, da desconfiança e do medo em relação ao outro ou, em contrapartida, o despertar do espírito de generosidade, o apoio mútuo, a empatia e a ação fraterna. Ambas as reações parecem até ser legitimadas em tempos de crise. Mas convém analisar em qual dos comportamentos mencionados há maior propensão à abertura de abismos sociais, violência estrutural, ausência de comprometimento e de participação social, descaso com o interesse coletivo e com a valorização das pluralidades pessoais, locais, regionais, etc.

A resposta parece apontar para a seguinte premissa: a relação interpessoal e institucional que tem como base a reciprocidade, a cooperação, a boa-fé, a fraternidade, tendem a aumentar o nível de socialidade do ambiente e a promover maior coesão social e territorial, atenuando os vazios de injustiças e devolvendo dignidade às pessoas. Contrastando, portanto, com o tipo de comportamento (ação/omissão) de exclusão e marginalização social, o princípio da fraternidade desponta como norte para um novo modelo relacional, ou seja, um modelo em que as ações de reciprocidade passam a produzir a socialidade essencial às relações:

La fraternidad, en la medida en que predispone los animos hacia la cooperación el servicio del bien comun, influye favorablemente sobre el funcionamiento econômico al estimular tanto la oferta como la demanda; así como tambien favorecer la reducción de las tasas de pobreza y exclusión (LIZANA, 2017, p. 42).

Verificamos, portanto, que a pandemia instalada em 2019 provocou a real necessidade de repensar práticas econômicas, políticas, sociais, mas também repensar valores e princípios, intrínsecos aos seres humanos, agregando uma nova pedagogia no combate a esta crise, supedaneada em práticas horizontais de cooperação, solidariedade e fraternidade.

Ademais, esses tempos também estão evidenciando a verdadeira essência da natureza humana: feito indivíduo, nasce em sociedade; é um ser, por natureza, social, comunitário, relacional; logo, com propensão a cooperar com o outro, garantindo um clima favorável à própria convivência social.

Assim sendo, o binômio justiça-fraternidade orientado a este ser coletivo e às relações por ele estabelecidas corresponde a um dos modos de rever e corrigir as assimetrias relacionais, o que se verifica a partir de sua prática, invocada em experimentalismos, capaz de consolidar um novo momento geracional: o fraterno. 


\section{Experimentalismos Fraternais: desafios e perspectivas ${ }^{12}$}

É possível afirmar que a disseminação do vírus nos proporcionou, em vários aspectos, a mudança de olhar, seja para tentar compreender os limites impostos à nossa liberdade, seja para repensar a nossa forma de viver e de nos relacionar com o outro. O planeta Terra se reconhece como uma comunidade de vizinhança, a ação de um pode reverberar positiva ou negativamente no outro. Logo, o reconhecimento de habitar a mesma "casa comum" traz a reflexão de que tudo está interligado, assim temos responsabilidades comuns, transfronteiriças para com o outro, para com o planeta. Nesse ponto, a atual pandemia nos trouxe a oportunidade de dar vez à fraternidade, enquanto princípio de responsabilidade para com o próximo, permitindo um maior equilíbrio entre os direitos de liberdade e igualdade.

Porquanto, a liberdade, hoje restringida, não depende apenas de atos individuais, mas está vinculada à liberdade coletiva; “ (...) o vírus nos ensina que a liberdade não pode ser vivida sem o senso da solidariedade e que a liberdade separada da solidariedade é puro arbítrio" (RECALCATI, 2020, s/p). Do mesmo modo, a igualdade, por seus próprios fundamentos, existe em relação ao outro (princípio de referência a algo ou alguém), inaugurando a geração dos direitos sociais, com a presença do Welfare State, convocando as institucionalidades a se reorganizarem em função da imprevisibilidade dos tempos, no sentido de minimizar os impactos da crise, associando-se, inclusive ao setor privado, para juntos regularem a economia, deixando de lado o paradigma capitalista de buscar o lucro a qualquer custo.

Com base nessas premissas, os experimentalismos fraternais aqui expostos buscam apontar os desafios a serem superados e as novas perspectivas que norteiam o "novo normal".

Ao iniciar o isolamento social, a mobilização de muitos voluntários foi imediata, das atitudes mais simples às mais complexas. A fragilidade humana fez com que as pessoas se colocassem no lugar umas das outras e criassem alguns mecanismos para minimizar os danos de cada um. Muitos noticiários reportaram diversas ações solidárias que passaram a acontecer nesse período. A jornalista Eliane Brum (2020, s/p) relata que: "Isoladas em casa, as pessoas passaram a fazer o que não faziam antes: enxergar umas às outras, reconhecer umas às outras, cuidar umas das outras. Justo agora, quando ficou muito mais difícil, parece ter se tornado mais fácil alcançar o outro".

12 Neste tópico nos inspiramos na ideia de "experimentalismos democráticos" nos moldes desenvolvidos por SANTOS e AVRITZER (in Democratizar a democracia. Os caminhos da democracia participativa. Porto: Edições Afrontamento, 2003). Naquele contexto, os autores se referem a formas de experimentação não convencionais, que se originaram de "novas gramáticas sociais" e, ao transporem os modelos hegemônicos, podem conter potenciais emancipatórios. Desafia-nos a pensar novos modos do agir, mesmo que não necessariamente se proponham a serem modelos para todos. 
Além da atuação da sociedade civil através de projetos e ações voluntárias, os políticos precisaram atuar de maneira positiva e objetiva para tentar mitigar os efeitos da pandemia. No Senado houve convergência de representações dos diferentes partidos para a aprovação do projeto de autoria da deputada Benedita da Silva (PT-RJ) que repassa uma verba de R \$ 3 bilhões ao setor cultural, intitulada "Lei Aldir Blanc" (SAID, 2020). Provavelmente, em outras condições, dificilmente se observaria a convergência de distintos partidos. Não seria algo "natural" vermos a oposição votando a favor de projetos do governo. O senador Jaques Wagner, relator da matéria, pronunciou-se a respeito ${ }^{13}$, demonstrando essa mudança de mentalidade do individual para o fraternal, deixando para trás as diferenças e colocando como centro do diálogo o bem comum.

Algumas empresas privadas brasileiras também aderiram a iniciativas de promoção da dignidade humana e da fraternidade, buscando ajudar seus funcionários, colaboradores, clientes e demais pessoas, a fim de evitar demissões em massa. Algumas, inclusive, mudaram seu produto-fim ao passarem a produzir máscaras ou produtos de higiene a base de álcool ${ }^{14}$. Outras empresas do setor privado se uniram ao poder público para prestarem seus serviços em prol da saúde pública, como fez uma empresa de mobilidade via aplicativo na cidade de Caruaru-PE ao disponibilizar em maio deste ano "mil corridas gratuitas ao Consórcio dos Municípios de Pernambuco (Comupe) o que correspondeu a cerca de 700 viagens garantidas para os profissionais que estão na linha de frente ao combate do novo coronavírus" (PREFEITURA DE CARUARU, 2020).

São experiências como essas que nos dão indicativos de que podemos projetar melhorias para a sociedade e atenuar os vazios de justiça e de práticas fraternas. A fraternidade enfatiza a responsabilidade de todas as pessoas com a construção de novas realidades, não deixando apenas para o Poder Público as ações afirmativas de combate às desigualdades sociais, sendo, portanto, um princípio participativo, de relacionamentos mútuos. A construção de práticas fraternas, para além do mero assistencialismo, é uma forma de concretizar a justiça social através da cooperação mútua entre as pessoas e o poder público, conforme atesta Chiara Lubich:

A fraternidade é um empenho que: favorece o desenvolvimento autenticamente humano do país sem isolar na incerteza do futuro as categorias mais fracas, sem

\footnotetext{
13 “Sou um homem de oposição, mas acho que há momentos em que nós podemos superar diferenças para nos encontrar naquilo que faz bem à nação brasileira e ao povo brasileiro. A cultura é nossa marca, de Sul a Norte, de Oeste a Leste. Espero que Sua Excelência, o presidente da República, possa aprovar o texto sem vetos para que esse recurso possa rapidamente, como no texto prevê, em 15 dias, chegar à ponta para que o remédio não encontre o paciente já em situação terminal". (SAID, 2020, s/p)

${ }^{14}$ Conforme RUIZ (2020, s/p): "Na época de pandemia, como nas outras grandes crises, se afirma que as empresas também são um patrimônio comunitário e cumprem uma função social que não se pode deixar morrer. De repente, em época de pandemia, como em outras grandes crises, se abandona a doutrina do liberalismo econômico e se apela para o socorro público como única solução".
} 
excluir outras do bem-estar, sem criar novas pobrezas; salvaguarda os direitos da cidadania e o acesso à própria cidadania, abrindo uma esperança a todos que buscam a possibilidade de uma vida digna em nosso país, o qual pode mostrar a própria grandeza oferecendo-se como pátria para quem perdeu, ajuda a pesquisa científica e a invenção de novas tecnologias, salvaguardando, ao mesmo tempo, a dignidade da pessoa humana do primeiro ao último instante de sua vida fornecendo sempre as condições para que cada pessoa possa exercer a própria liberdade de escolha e possa crescer assumindo responsabilidades. (LUBICH, 2003, p. 309-310).

Percebemos, portanto, que a fraternidade busca dar uma nova autonomia e liberdade a cada indivíduo para que possa (re) construir-se em suas próprias atitudes, sendo corresponsável pela preservação dos direitos fundamentais dos demais em uma relação de reciprocidade, característica também da justiça relacional.

O binômio justiça-fraternidade oferece, portanto, um contributo muito além daquele que nutre as necessidades físicas imediatas de cada indivíduo, principalmente, em tempos de emergências, pois busca construir uma realidade onde cada ser humano seja capaz de exercer sua cidadania para além da esfera individual, ao incluir os invisíveis e as invisibilidades das realidades mascaradas de nosso país, devolvendo-lhes dignidade e justiça.

\section{Considerações Finais}

Sem a pretensão de nos fecharmos às conclusões, passamos a apresentar os arremates que marcam o termo deste trabalho e que se abrem para desdobramentos futuros.

a. A pandemia tanto desvelou quanto agravou a desigualdade social brasileira, de modo que entendemos ser possivel afirmar que o oposto dessa desigualdade não é simplesmente igualdade, mas dignidade. Afinal, não obstante os avanços significativos (mas também retrocessos) no horizonte da nossa igualdade formal, prevista na Constituição Federal de 1988 em mais de um dispositivo, bem como na legislação infraconstitucional, as distâncias que nos separam enquanto brasileiros estão além do que se vê no ordenamento jurídico. Nestes contextos, em que tantas vezes observamos a distância entre aquilo que fora previsto na norma e a sua efetividade, a fluidez normativa, especificamente referente aos direitos sociais, se agrava e nos leva para um terreno muito preocupante, sendo difícil pensar em dignidade humana sem que a grande parte dos brasileiros e brasileiras seja efetivado (ao menos) o núcleo de um mínimo existencial à uma existência digna.

b. O binômio justiça-fraternidade parece ser uma proposta capaz de atenuar os vazios de justiça social, na medida em que a ação fraterna nas relações interpessoais e institucionais pode provocar uma mudança cultural paradigmática, consequentemente contribuindo para substituir as relações de hierarquia, poder e subordinação, em relações horizontais, em que o coletivo e o 
indivíduo importam. Assim, ajustar as assimetrias das desigualdades sociais, não é tarefa simples, pois pressupõe a abertura das relações institucionais e interpessoais para uma verdadeira mudança de paradigma cultural, que envolve, a passagem do mero individualismo para o fraternalismo, do eu, para o outro, reconhecendo no outro, um ser humano igual a mim, com os mesmos direitos e deveres de uma vida digna.

c. A pandemia também foi capaz de nos mostrar o que é essencial para alcançar uma vida digna, desmascarando as realidades impregnadas de hábitos de consumo desenfreado, de desperdício de alimentos, de excedente de produção e do descartável, fontes das maiores gerações de pobreza e exclusão. Com base nesta realidade desmascarada, se é verdade que as relações existentes nas estruturas sociais (institucionalidades) se influenciam reciprocamente, a inserção de um novo paradigma a partir do binômio justiça-fraternidade, pode introduzir mudanças nos comportamentos sociais, políticos e econômicos, as quais podem influenciar a administração pública, alterando os resultados do funcionalismo público, ao fazer valer os preceitos constitucionais, dispostos no art. 37 da $\mathrm{CF} / 88$, especificamente os de legalidade, eficiência, moralidade e transparência para com a sociedade.

d. A esperança de ver nascer um novo mundo pós-pandemia não pode configurar uma mera utopia de ingênuos, mas uma construção coletiva que depende da decisão de todos e de cada um. Os indivíduos de determinada sociedade, muitas vezes, depositam apenas no poder público a obrigação de proporcionar uma nova realidade, desconsiderando que a construção da política, é um chamado a cada cidadão que deve protagonizar e fazer jus a seus direitos e deveres, sendo corresponsável junto com o Estado, formando uma cogovernança política.

e. A construção de um novo enfoque de justiça que prioriza a qualidade das relações estabelecidas parece se aproximar de um modelo sistêmico mais justo, em que são relevantes a cooperação, a boa-fé relacional, a visão em prol do outro. Este parece ser um momento propício para repensar e atualizar as práticas e políticas públicas de hoje, a fim de atenuar os abismos dessas desigualdades, integrando reciprocamente: a atuação do Estado (serviços públicos) + setor empresarial (mercado) + participação social (cada pessoa importa), a fim de recuperar o caminho do desenvolvimento social (LIANZA, 2012), preenchendo ou atenuando os vazios de justiça social.

f. A fraternidade parece ser um caminho seguro para a sociedade fazer a travessia desses tempos dificeis, pois se trata de um princípio capaz de enfatizar a necessidade de se pensar e se viver os valores humanos, que traz à tona relações horizontais, de corresponsabilidade e que busca uma revolução intelectual como fonte de transformação social. Ao trilhar esse caminho, a educação para a fraternidade pode concretizar nas presentes e nas futuras gerações a esperança 
de um mundo mais justo. Por sua vez, avançar rumo ao novo que nos espera, implica ousar no empenho de renovar os ambientes relacionais a partir desta nova pedagogia que vê na fraternidade um campo vasto para produção de saberes.

\section{REFERÊNCIAS}

ABRAMS, Elissa; SZEFLER, Stanley. COVID-19 and the impact of social determinants of health. The Lancet journals as it is published 18.may.2020. Disponível em https://doi.org/10.1016/S2213-2600(20)30234-4 Acesso em:28.jun.2020

ARENDT, Hannah. Origens do totalitarismo. São Paulo: Companhia das Letras, 1989.

BARROSO, Luís Roberto. A Dignidade da Pessoa Humana no Direito Constitucional Contemporâneo: A construção de um conceito jurídico à luz da jurisprudência mundial. Belo Horizonte: Fórum, 2013.

CANOTILHO, J. J. G. Metodología "fuzzy" y "camaleones normativos" en la problemática actual de los derechos económicos, sociales y culturales. Derechos y Libertades: Revista del Instituto Bartolomé de las Casas. Universidad Carlos III de Madrid. 1998, pp.35-50 Disponível em http://hdl.handle.net/10016/1319.

CARUARU. Prefeitura de Caruaru firma parceria com empresa de mobilidade via aplicativo. Disponível em: https://caruaru.pe.gov.br/prefeitura-de-caruaru-firma-parceria-com-empresade-mobilidade-via-aplicativo/. Acesso em: 28.jun.2020.

CNS. Nota pública. Disponível em http://conselho.saude.gov.br/ultimas-noticias-cns/1231nota-cns-lamenta-as-50-667-mortes-por-covid-19-no-brasil-um-marco-evitavel-causado-pelodescaso-do-estado. Acesso em: 25.jun.2020.

HOLMES, S.; SUNSTEIN, C. R. The Cost of Rights: Why Liberty Depends on Taxes. New York, London: W. W. Norton \& Company, 1999.

LAZZARIN, Sonilde K. . A Ética da Fraternidade: o reconhecimento do outro e a educação para a fraternidade. In: BARZOTTO, Luciane Cardoso; GUEDES, Priscila Dal Ponte Amado; GUEDES, Gabriel Pinto. (Org.). Direito e Fraternidade: em busca de respostas. Porto Alegre: Sapiens, 2016, p. 249-286.

LEMOS, Roberta; REGO, Sergio [et al] Mistanásia hoje- pensando nas desigualdades sociais e a pandemia COVID-19. 2020. DOI: 10.13140/RG.2.2.16737.94568 Disponível em https://portal.fiocruz.br/sites/portal.fiocruz.br/files/documentos/mistanasia_hojepensando_nas_desigualdades_sociais_e_a_pandemia_covid-19_doi_pdf. Acesso em: 28.jun. 2020

LIZANA, Antonio García. Codicia y Fraternidad en la Gran Recesión. In: Márquez Prieto, Antonio (Coord.). Justicia Relacional y Principio de Fraternidad. Pamplona: Aranzadi, 2017. 
LUBICH, Chiara. Ideal e Luz. Pensamento, Espiritualidade e Mundo Unido. São Paulo: Cidade Nova, 2003.

MENDES, Gilmar Ferreira. A dignidade da pessoa humana na Constituição Federal de 1988 e sua aplicação pelo Supremo Tribunal Federal. Observatório da Jurisdição Constitucional. Ano 6, no. 2, jul./dez. 2013. ISSN 1982-4564. Disponível em https://www.portaldeperiodicos.idp.edu.br/observatorio/article/view/915/614. Acesso em: 28 jun. 2020

MINAYO, Maria Cecília de Souza; FREIRE, Neyson Pinheiro. Pandemia exacerba desigualdades na Saúde [a ser publicado na Ciênc. saúde coletiva] [online]. SciELO em Perspectiva, 2020 [acesso 18 Maio 2020]. Disponível em: https://blog.scielo.org/blog/2020/05/12/pandemia-exacerba-desigualdades-na-saude-a-serpublicado-na-cienc-saude-coletiva/.

MIRANDA, Saulo Silva. Socialidade e Justiça Relacional. In: ANDRADE, Fernando Gomes de; LOPES, Paulo Muniz; MACHADO, Carlos Augusto Alcântara. Ética, Direito e

Democracia: em busca de um novo paradigma de justiça (Anais do III Congresso Nacional de Comunhão e Direito). Caruaru, 2016.

RECALCATI, Massimo. La nuova fratellanza. In: La Repubblica. 13 marzo 2020. Disponível em:https://rep.repubblica.it/pwa/commento/2020/03/13/news/coronavirus_la_nuova_fratellan za_liberta_-251230782/. Acesso em: 16 jun.2020.

PRIETO, Antonio Márquez. Justicia Relacional y Fraternidad. In: BAGGIO, Antonio Maria; COSSEDU, Adriana; PRIETO, Antonio Márquez. Fraternidad y Justicia. Granada: Comares, 2012, p. 55-89.

PRIETO, Antonio Márquez. Repensar la justicia social. Enfoque relacional, teoría de juegos y relaciones laborales en la empresa. Pamplona: Thomson-Aranzadi, en la colección The Global Law Collection, 2008.

RIBEIRO, Darcy. O povo brasileiro: a formação e o sentido do Brasil. São Paulo: Companhia das Letras, 2006.

RUIZ, Castor M. M. Bartolomé. Pandemia e as falácias do homo economicus. Publicado em 19 abril de 2020. Disponível em: http://www.ihu.unisinos.br/78-noticias/598157pandemia-e-as-falacias-do-homo-economicus. Acesso em: 08 jun. 2020.

SAID, Flávia. Senado aprova Lei Aldir Blanc, que dá ajuda de R 3 bilhões ao setor cultural. Congresso em foco. UOL. 04 jun. 2020. Disponível em:

https://congressoemfoco.uol.com.br/legislativo/senado-aprova-lei-aldir-blanc-que-da-ajudade-r-3-bilhoes-ao-setor-cultural/. Acesso em: 17 jun. 2020.

SCHWARCZ, Lilia Moritz. Sobre o autoritarismo brasileiro. São Paulo: Companhia das Letras, 2019.

SOUZA, Jessé (Org.) A invisibilidade da desigualdade brasileira. Belo Horizonte: Editora UFMG, 2006. 
STEVANIM, Luiz Felipe. Vulnerabilidades que aproximam. RADIS (publicação impressa e digital da Fundação Oswaldo Cruz). N.212 | MAI 2020. Disponível em https://radis.ensp.fiocruz.br/phocadownload/revista/Radis212_web.pdf. 